\title{
LIFETIME PERFORMANCE TRAITS FOR HOLSTEIN FRIESIAN CATTLE RAISED IN EGYPT
}

\author{
H. O. Alhammad ${ }^{1}$, U. M. El-Saied ${ }^{2}$, M. A. M Ibrahim ${ }^{1}$, and A. A. Nigm ${ }^{1}$ \\ 1- Department of Animal Production, Faculty of Agriculture, Cairo University, \\ Giza, Egypt, 2- Animal Production Research Institute, Ministry of Agriculture and \\ Land Reclamation, Dokki, Giza, Egypt
}

\section{SUMMARY}

A total of 5662 lactation records for 1029 Holstein cows raised in three commercial herds was used in the present study to determine the strength of the phenotypic relationship between productive, reproductive and lifespan traits. The study took into account lifespan traits (lifetime, productive life, lifetime days in milk and lifetime score), lifetime milk yield and reproductive traits (age at first calving and calving interval). Milk yield was calculated per day of lifetime, productive life and lifetime days in milk. Partial lifespan traits were considered for the first three parities.

The statistical model included herd, year of birth and season of birth of the cow as fixed effects. Year of birth contributed significantly to variation in all traits. Herd showed significant effect on all the traits except for milk per-day of productive life and milk per-day of lifetime days in milk. Season of birth showed a significant effect on all lifespan traits. Milk/d of lifetime days in milk was added to the model as a fixed effect with four levels according to mean and SD of milk/d of lifetime days in milk when analyzing lifespan traits only. It significantly contributed to explaining the variation in all lifespan traits with high percentage of variance explained averaging 41.27\%. Lifetime (LT) averaged 3200 d, productive life (PL) accounted for $75 \%$ of LT while lifetime days in milk represented $64 \%$ and $85 \%$ of LT and PL, respectively. During lifetime, cows gave an average of 5.5 parities. Milk per-day of lifetime, per productive life and lifetime days in milk averaged $10.76 \mathrm{~kg}, 14.60 \mathrm{~kg}$ and $17.13 \mathrm{~kg}$, respectively. High correlations were recorded between lifespan traits and lifetime milk yield (0.92-0.97). Partial lifetime ( 2 \& 3 parities) per-day of milk yield had high correlation (0.71-0.92) with total lifetime per-day of milk yield. Therefore, good use of these traits would be helpful in determining best individuals early in life.

\section{Keywords: Phenotypic parameters, lifetime, Holstein Friesian}

\section{INTRODUCTION}

Lifetime can be seen as a composite of production, health, and reproduction (Mulder and Jansen, 2001). Culling decision is a part of the whole farming process, and lifetime is determined by culling decisions of individual producers (Mwansa, 1997). Culling based on low milk production is often referred to as voluntary culling, and culling based on health or reproductive problems is normally termed as involuntary culling (Vollema and Groen, 1996; Boettcher et al., 1999b; and

Issued by The Egyptian Society of Animal Production 
Cruickshank, 2002). Therefore, the length of an animal's productive life reflects the ability of the cow to not be culled.

In the countries with developed cattle breeding, the productive life of cows is shortened due to the increase in their producing capacity (Powell, 1985). Mulder and Jansen (2001) defined a profitable cow as the one that can hold a high production level for a long time, with an acceptable reproduction and without serious health problems. Because of its effect on economic performance, lifetime has been seen as a trait of interest for animal breeders, in general, and dairy breeders, in particular (Allaire and Gibson, 1992; Dekkers et al., 1994; Perez-Cabal and Alenda, 2003). The objectives of this work were to characterize lifetime performance traits for Holstein Friesian cows raised in commercial herds in Egypt and to determine the strength of the phenotypic relationships between total and partial lifespan traits measured during the first three parities including productive and reproductive performance in Holstein Friesian cows in Egypt.

\section{MATERIALS AND METHODS}

\section{Animals and herd management}

This study was carried out on three commercial herds of Holstein cows belonging to El-Salhia Agricultural Company, Ismailia Governorate (East to the south of Nile Delta). All animals were imported from USA as pregnant heifers since 1982.

All cows were kept under similar feeding and management systems. All year round, cows were fed concentrates and corn silage according to their body weight and milk production. During winter and spring months, animals were supplied with Egyptian clover (Trifolium alexandrium), while, beets, maize and green sorghum (Sorghum vulgar) were available during summer and autumn. In addition, rice straw was available all the year round. Free clean water and mineral mixture were always available.

Artificial insemination was practiced during the first heat period following the $45^{\text {th }}$ day post-partum using frozen semen imported from the USA. Pregnancy was detected by rectal palpation 60 days after the last service. Cows were machine milked twice daily until two months before their expected calving dates. Then if they did not go dry, they were dried off gradually by milking them once a day until completely dried off. Milk per lactation was estimated through a set of test day records taken at monthly intervals.

\section{Data and general edits}

A total of 5662 complete lactation records for 1.49 cows, were used. All cows were required to have consecutive lactations, starting with the first. Birth dates between 1981 and 1983 were required, calving dates were between 1982 and 1994 inclusive, and therefore the youngest cows had at least 11 years of opportunity for life. Age at first calving was between 18 and 40 months and calving interval was restricted to $300-600$ days.

\section{Traits}

Four variables related to the life of the cow were considered in the present study including: 
Total lifetime (LT): number of days between birth and disposal (voluntary or involuntary), Productive Life (PL): length of time between first calving and the last dry date, Lifetime days in milk (LDIM): total number of days in milk (DIM) during lifetime and Lifetime score: number of lactations a cow survived.

Two intervals of time that are unprofitable from a milk production standpoint are the period from birth to first calving and dry periods (Lormore and Galligan, 2001). These periods represent nonproductive days that dilute the profit of production per day of life. Therefore, other measures for lifespan were added that considered both productivity and lifespan. These measures included, milk / $\mathrm{d}$ for each of LT, PL, and LDIM.

Partial lifetime traits were also calculated for the first three calving. Traits included were age at each calving; PL, LDIM, LMY and milk yield per day of LT, PL, and LDIM during the first three parities.

\section{Statistical Analysis}

Analyses of variance and estimation of fixed effects were calculated using the General Linear model (GLM) procedure of SAS (SAS, 1999). Phenotypic correlations were estimated through the CORR procedure of the same program. The following statistical model was applied to analysis fixed effects on lifetime traits:

$\mathbf{Y}_{\mathbf{i j k m}}=\mathbf{H}_{\mathbf{i}}+\mathbf{Y} \mathbf{B}_{\mathbf{j}}+\mathbf{S}_{\mathbf{k}}+\mathbf{e}_{\mathbf{i j k m}}$

where:

$\mathrm{Y}_{\mathrm{ijklm}}=$ productive and reproductive total or partial lifetime traits;

$\mathrm{H}_{\mathrm{i}} \quad$ fixed effect of the $\mathrm{i}^{\text {th }}$ herd, $\quad(\mathrm{i}=1,2,3)$;

$\mathrm{YB}_{\mathrm{j}}=$ fixed effect of the $\mathrm{j}^{\text {th }}$ year of birth, $(\mathrm{j}=1,2)$;

$\mathrm{S}_{\mathrm{k}}=$ fixed effect of the $\mathrm{k}^{\text {th }}$ season of birth, $(\mathrm{k}=1,2,3,4)$, where $1=$ December, January and February, 2= March through May, 3= Jun through August and 4= September through November ; and

$\mathrm{e}_{\mathrm{ijkm}}=$ error term.

The percentage of variance explained by each fixed effect was estimated from a univariate analysis using the VARCOMP procedure of SAS (SAS, 1999).

Milk/d of lifetime days in milk was added to the above mentioned model as a fixed effect with four levels when analyzing lifespan traits (LT, PL, LDIM and lifetime score). The four levels were determined according to mean and SD of milk/d of LDIM as: $\leq 14.38,(>14.38-17.13),(>17.13-19.89)$ and $>19.891$ of milk/d of LDIM, respectively.

\section{RESULTS AND DISCUSSION}

\section{Descriptive statistics for total and partial lifetime performance traits}

Phenotypic means, standard deviations (SD), minimums (Min.), maximums (Max.), and coefficients of variation (CV) for total and partial lifetime performance traits are given in tables 1 and 2, respectively. The coefficients of variation for lifespan traits (LT, PL, LDIM, and lifetime score) were high (23.6-31.6). While, $\mathrm{M} / \mathrm{dLT}$, and M/dPL, M/dLDIM, had lower CV (16.1-22.1). The standardization effect on per day traits by days of life may explain this difference in $\mathrm{CV}$. The highest CV was for LMY. Total LT mean obtained in this study was 3200 d. (105.3 months). The reviewed estimates ranged between 59.9 month for Holstein cattle in USA (Dentine et al., 1987) and 76.4 month for Friesian cattle in Egypt (Halawa, 2007). 
PL represents $75 \%$ of total LT of the cow, while LDIM represented $64 \%$ and $85 \%$ of LT and PL, respectively. Average lifetime score (number of given parities during lifetime) was 5.5 and ranged from 2 to 9 parities. The present lifetime score is slightly higher than that reported by Atil and Khattab (1999) on another herd of Holstein Friesian cattle in Egypt. Non productive periods (time from birth to first calving and cumulative dry periods during lifetime) averaged $711 \mathrm{~d}$. and $447 \mathrm{~d}$., respectively. Madani et al. (2008) reported that under semi arid conditions, heifers calving with an average age at first calving of 24 to 30 months produced less milk during second lactation, fewer cumulative milk yield for the first three lactations and for total lifetime production, and had lower reproductive performances during first parity when compared to cows freshening at older ages.

\section{Analysis of variance of total lifetime performance traits}

Significance level and percentage of variance explained by fixed effects for total lifetime performance traits are shown in table 3. Year of birth contributed significantly to variation in all traits. Except for milk per day of productive life and milk per day of lifetime days in milk, herd showed significant effect on all the traits in table 3. Season of birth showed a significant effect on all the lifespan traits.

With regard to the results of percentage of variance explained by the effects; more variance was explained by herd for lifetime, productive life, lifetime days in milk, lifetime score, and reproductive traits (age at first calving and calving interval) than that explained by year of birth or season of birth. In contrast, more variance was explained by year of birth for lifetime, lifetime milk yield, and per day milk traits than that explained by herd or by season of birth. Season of birth accounted for less variance than that explained by other fixed effects for all traits. The percentage of variance explained by herd, year of birth, and season of birth averaged 5.63, 20.40, and $0.44 \%$, respectively. Some non genetic factors (reproductive management of the herd, climatic differences, nutrition level, etc.) might be a reason for this result.

Table 1. Phenotypic means, standard deviations (SD), minimums (Min.), maximums (Max.), and coefficients of variation (CV) for total lifetime performance traits

\begin{tabular}{lccccc}
\hline Trait & Mean & SD & Min. & Max. & CV\% \\
\hline LT, d & 3200 & 754 & 1422 & 5144 & 23.6 \\
PL, d & 2399 & 759 & 604 & 4397 & 31.6 \\
LDIM, d & 2042 & 644 & 549 & 3622 & 31.6 \\
LT score & 5.5 & 1.5 & 2 & 9 & 26.8 \\
LMY, 1 & 35741 & 14396 & 6894 & 77689 & 40.3 \\
M/dLT, 1 & 10.76 & 2.38 & 4.7 & 16.7 & 22.1 \\
M/dPL, 1 & 14.60 & 2.35 & 9.6 & 20.7 & 16.1 \\
M/dLDIM, 1 & 17.13 & 2.76 & 11.8 & 24.6 & 16.1 \\
Age1C, d & 711 & 50.6 & 570 & 960 & 7.1 \\
CI & 439 & 35 & 343 & 547 & 8 \\
\hline
\end{tabular}

Number of analyzed records $=1029$ for all variables.

$\mathrm{LT}=$ Lifetime, $\mathrm{PL}=$ productive life, $\mathrm{LDIM}=$ lifetime days in milk, $\mathrm{LT}$ score $=$ lifetime score; number of given parities during lifetime, $\mathrm{LMY}=$ lifetime milk yield, $\mathrm{M} / \mathrm{dLT}=$ milk per day of lifetime, $\mathrm{M} / \mathrm{dPL}=$ milk per day of productive life, $\mathrm{M} / \mathrm{dLDIM}=$ milk per day of lifetime days in milk, Age1C = age at first calving, $\mathrm{CI}=$ Calving interval ; average interval between successive lactations. 
Table 2. Phenotypic means, standard deviations (SD), minimums (Min.), maximums (Max.), and coefficients of variation (CV) for partial lifetime performance traits

\begin{tabular}{lccccc} 
Trait & Mean & SD & Min. & Max. & CV\% \\
\hline Age1C, d & 711 & 50.6 & 570 & 960 & 7.1 \\
Age2C, d & 1106 & 73.7 & 962 & 1428 & 6.7 \\
Age3C, d & 1522 & 91.2 & 1303 & 1957 & 6 \\
PL2, d & 734 & 67.8 & 572 & 1023 & 9.2 \\
PL3, d & 1174 & 85.7 & 961 & 1525 & 7.3 \\
LDIM1, d & 323 & 48.4 & 230 & 489 & 15 \\
LDIM2, d & 662 & 70 & 499 & 969 & 10.6 \\
LDIM3, d & 1025 & 87 & 790 & 1386 & 8.5 \\
MY1, 1 & 4746 & 1122 & 3036 & 9841 & 23.7 \\
MY2, 1 & 10524 & 2170 & 6480 & 18932 & 20.6 \\
MY3, 1 & 17395 & 3457 & 10140 & 29358 & 19.9 \\
M/dLT1, 1 & 4.3 & 0.93 & 2.6 & 7.7 & 21.8 \\
M/dLT2, 1 & 6.9 & 1.35 & 4.4 & 11.1 & 19.6 \\
M/dLT3, 1 & 8.9 & 1.69 & 5.4 & 13.7 & 19.1 \\
M/dPL2,1 & 14.3 & 2.60 & 9.8 & 24.7 & 18.1 \\
M/dPL3,1 & 14.8 & 2.73 & 9.6 & 22.4 & 18.4 \\
M/dLDIM1,1 & 14.7 & 2.64 & 10.6 & 30.8 & 17.9 \\
M/dLDIM2,1 & 15.9 & 2.78 & 11.5 & 26.5 & 17.5 \\
M/dLDIM3,1 & 17 & 3 & 11.7 & 25.9 & 17.8
\end{tabular}

Age1C $=$ Age at first calving, Age2C $=$ age at second calving, Age $3 \mathrm{C}=$ age at third calving, PL2 = 2parity productive life, PL3 = 3-parity productive life, LDIM1 = first parity lifetime days in milk, LDIM2 = 2-parity lifetime days in milk, LDIM3 = 3-parity lifetime days in milk, MY1 = milk yield of first parity, MY2 = cumulative milk yield of first 2 parities, MY3 = cumulative milk yield of first 3 parities, M/dLT1 = milk per day of lifetime at end of first parity, M/dLT2 = milk per day of lifetime at end of second parity, $\mathrm{M} / \mathrm{dLT} 3=$ milk per day of lifetime at end of third parity, M/dPL2 = milk per day of productive life at end of second parity, M/dPL3 = milk per day of productive life at end of third parity, M/dLDIM1 = milk per day of lifetime days in milk at end of first parity, M/dLDIM2 = milk per day of lifetime days in milk at end of second parity, M/dLDIM3 = milk per day of lifetime days in milk at end of third parity.

\section{Lifespan traits and milk production level}

Milk per day of lifetime days in milk was included in the model as a fixed effect with 4 levels in view of the mean of the trait and its standard deviation to adjust lifespan traits (lifetime, productive, lifetime days in milk, and lifetime score) for milk production level. Milk production level contributed significantly $(P<0.001)$ to variation in all lifespan traits (Table 3). Least squares means of total lifespan traits as affected by milk production level (four levels started with the lowest level "1") are shown in table 4 . The relationship between milk production level and lifespan traits is clearly positive and successive. All lifespan traits increased gradually with milk production level. Dentine et al. (1987) stated that if increases in overall fitness permit more voluntary culling, increasing potential for a longer life can be beneficial even if average lifespan are not lengthened. 
Table 3. Analysis of variance of total lifetime performance traits

\begin{tabular}{|c|c|c|c|c|c|c|c|c|c|}
\hline \multirow[t]{2}{*}{ Trait $^{1}$} & \multicolumn{4}{|c|}{$F$-Value and significance level } & \multirow[t]{2}{*}{$\begin{array}{c}\% \\
\text { Error }\end{array}$} & \multicolumn{4}{|c|}{$\begin{array}{l}\% \text { of variance explained by the } \\
\text { effect }\end{array}$} \\
\hline & Herd & Year & Season & MPL & & Herd & Year & Season & MPL \\
\hline $\mathrm{LT}, \mathrm{d}$ & $14.05 * * *$ & $17.19 * * *$ & $3.70^{*}$ & $125.79 * * *$ & 2.00 & 3.75 & 4.19 & 0.61 & 41.68 \\
\hline PL, d & $18.47 * * *$ & $12.57 * * *$ & $3.75^{*}$ & $124.73 * * *$ & 2.00 & 5.00 & 2.99 & 0.62 & 41.43 \\
\hline LDIM, d & $17.20 * * *$ & $15.29 * * *$ & $3.72 *$ & $127.95 * * *$ & 2.00 & 4.58 & 3.65 & 0.61 & 41.81 \\
\hline Score & $24.24 * * *$ & $7.55 * *$ & $4.05^{* *}$ & $117.24 * * *$ & 2.00 & 6.45 & 1.72 & 0.70 & 40.17 \\
\hline LMY, 1 & $9.74 * * *$ & $74.31 * * *$ & $1.93^{\mathrm{NS}}$ & - & 6.00 & 3.38 & 20.13 & 0.33 & - \\
\hline $\mathrm{M} / \mathrm{dLT}, 1$ & $11.28 * * *$ & $209.58^{* * *}$ & $1.85^{\mathrm{NS}}$ & - & 2.00 & 2.98 & 42.14 & 0.22 & - \\
\hline $\mathrm{M} / \mathrm{dPL}, 1$ & $1.01^{\mathrm{NS}}$ & $298.60 * * *$ & $1.89^{\mathrm{NS}}$ & - & 2.00 & 0.00 & 51.46 & 0.19 & - \\
\hline M/dLDIM,1 & $2.06^{\mathrm{NS}}$ & $341.49 * * *$ & $2.14^{\mathrm{NS}}$ & - & 1.00 & 0.21 & 55.16 & 0.23 & - \\
\hline Age $1 \mathrm{C}, \mathrm{d}$ & $98.32 * * *$ & $100.55^{* * *}$ & $2.11^{\mathrm{NS}}$ & - & 2.00 & 24.37 & 20.16 & 0.28 & - \\
\hline CI & $15.69^{* * *}$ & $8.88^{* *}$ & $2.53^{\mathrm{NS}}$ & - & 16.00 & 5.60 & 2.41 & 0.62 & - \\
\hline
\end{tabular}

${ }^{1} \mathrm{LT}=$ Lifetime, $\mathrm{PL}=$ productive life, LDIM = lifetime days in milk, LT score = lifetime score; number of given parities during lifetime, $\mathrm{LMY}=$ lifetime milk yield, $\mathrm{M} / \mathrm{dLT}=$ milk per day of lifetime, M/dPL = milk per day of productive life, $\mathrm{M} / \mathrm{dLDIM}=$ milk per day of lifetime days in milk, Age1C = age at first calving, $\mathrm{CI}=$ Calving interval ; average interval between successive lactations. Year $=$ year of birth of the cow, Season= season of birth of the cow, MPL $=$ milk production level.

${ }^{*} P<0.05, * * P<0.01, * * * P<0.001 ; \mathrm{NS}=$ Not significant.

$2 \%$ of error was calculated as mean square error as a percentage from mean square of the model.

Table 4. Least squares means (X) and standard error (SE) of total lifespan traits as affected by milk production level

\begin{tabular}{|c|c|c|c|c|c|c|c|c|}
\hline \multirow{3}{*}{ Trait } & \multicolumn{8}{|c|}{ Milk production level } \\
\hline & \multicolumn{2}{|c|}{ Level 1} & \multicolumn{2}{|c|}{ Level 2} & \multicolumn{2}{|c|}{ Level 3} & \multicolumn{2}{|c|}{ Level 4} \\
\hline & $\mathrm{X}$ & SE & $\mathrm{X}$ & SE & $\mathrm{X}$ & SE & $\mathrm{X}$ & SE \\
\hline LT, d & $2396^{\mathrm{d}}$ & 53 & $3167^{\mathrm{c}}$ & 41 & $3355^{b}$ & 38 & $3802^{\mathrm{a}}$ & 52 \\
\hline PL, d & $1604^{\mathrm{d}}$ & 53 & $2371^{\mathrm{c}}$ & 41 & $2563^{\mathrm{b}}$ & 38 & $3007^{\mathrm{a}}$ & 52 \\
\hline LDIM, d & $1353^{d}$ & 45 & $2019^{c}$ & 35 & $2182^{b}$ & 32 & $2551^{\mathrm{a}}$ & 44 \\
\hline LT score & $4.0^{\mathrm{d}}$ & 0.10 & $5.4^{\mathrm{c}}$ & 0.08 & $5.8^{\mathrm{b}}$ & 0.07 & $6.7^{\mathrm{a}}$ & 0.10 \\
\hline
\end{tabular}

Means within a row followed by the different superscript letters are different at $\mathrm{P}<0.05$.

$\mathrm{LT}=$ Lifetime, $\mathrm{PL}=$ productive life, $\mathrm{LDIM}=$ lifetime days in milk, $\mathrm{LT}$ score = lifetime score; number of given parities during lifetime.

\section{Phenotypic correlations between total lifetime performance traits}

Table 5 shows estimates of phenotypic correlations between the studied total lifetime performance traits. This study considered four lifespan traits (LT, PL, LDIM, and lifetime score). Correlation between these traits ranged from 0.97 to 0.99 . The correlation between these traits and lifetime milk yield (LMY) were also high (0.93 with each of LT and PL and 0.92 with LDIM).

Milk per day traits considered in the present study include M/dLT, M/dPL, and M/dLDIM. Correlations among these traits were also high ( 0.90 between M/dLT and each of M/dPL and M/dLDIM and 0.98 between M/dPL and M/dLDIM). Milk/dPL and M/dLDIM had lower correlations with lifespan traits ranging from 0.40 to 0.45 , while, M/dLT had higher correlations with lifespan traits that ranged from 0.73 to 0.76 . 
Table 5. Phenotypic correlations among total lifetime performance traits

\begin{tabular}{|c|c|c|c|c|c|c|c|c|}
\hline Trait & LT & PL & LDIM & $\begin{array}{l}\text { LT } \\
\text { score }\end{array}$ & LMY & Age1C & $\mathrm{M} / \mathrm{dLT}$ & $\mathrm{M} / \mathrm{dPL}$ \\
\hline PL & 0.99 & & & & & & & \\
\hline LDIM & 0.99 & 0.99 & & & & & & \\
\hline LT score & 0.97 & 0.98 & 0.97 & & & & & \\
\hline LMY & 0.93 & 0.93 & 0.93 & 0.92 & & & & \\
\hline Age1C & -0.11 & -0.18 & -0.17 & -0.22 & -0.16 & & & \\
\hline $\mathrm{M} / \mathrm{dLT}$ & 0.73 & 0.75 & 0.75 & 0.76 & 0.91 & -.024 & & \\
\hline $\mathrm{M} / \mathrm{dPL}$ & 0.40 & 0.40 & 0.41 & 0.41 & 0.69 & -0.11 & 0.90 & \\
\hline M/dLDIM & 0.42 & 0.43 & 0.43 & 0.45 & 0.70 & -0.14 & 0.90 & 0.98 \\
\hline
\end{tabular}

$\mathrm{LT}=$ Lifetime, $\mathrm{PL}=$ productive life, $\mathrm{LDIM}=$ lifetime days in milk, LTscore= lifetime score ; number of given parities during lifetime, $\mathrm{LMY}=$ lifetime milk yield, Age $1 \mathrm{C}=$ age at first calving, $\mathrm{M} / \mathrm{dLT}=$ milk per day of lifetime, $\mathrm{M} / \mathrm{dPL}=$ milk per day of productive life, $\mathrm{M} / \mathrm{dLDIM}=$ milk per day of LDIM .

\section{Phenotypic correlations between total and partial lifetime performance traits}

Phenotypic correlations between partial LT performance traits and their corresponding total LT performance traits are in table 6. In general, first lactation for all partial LT performance traits had the lowest correlation with its corresponding total LT traits. Adding more information to first lactation increased the correlation gradually and notably. As expected, correlations increased with more information because early LT performance is a part of total LT performance (i.e. part-whole relationship). Both age at second calving and age at third calving did not correlate with total LT (-0.04 to 0.04$)$. While, weak negative correlation was found between age at first calving and total LT. Moreover, weak correlations were found between partial and total LT traits for PL and LDIM. However, cumulative milk yield from the first two and first three parities had moderate correlations $(0.45-0.56)$ with LMY during lifetime.

Among all partial LT performance traits, per-day milk yield traits had the highest correlations with total LT performance traits. The standardization effect on per-day milk yield traits by days of life may explain these high correlations.

Daily milk yield traits are of practical use since they are easy to be calculated at any time during LT of the cow. Moreover, they combine different productive and reproductive aspects through LT of the animal. Therefore, these traits may serve as an acceptable index to compare and evaluate the general performance of cows at any time during lifespan.

Phenotypic correlation is a basic step in establishing the strength of relationships among traits. Detailed genetic work is needed to study the heredity of LT traits in Holstein Friesian cattle raised in Egypt and to investigate genetic relationships among 
these traits. Such a study would be useful in supporting results of the present work and determining traits of interest and possibilities for genetic improvement.

Table 6. Phenotypic correlations $\left(r_{p}\right)$ of partial lifetime performance traits with their corresponding total lifetime performance traits

\begin{tabular}{|c|c|c|c|}
\hline $\begin{array}{l}\text { Partial } \\
\text { Lifetime trait }\end{array}$ & $\begin{array}{c}r_{g} \text { with } \\
\text { LT }\end{array}$ & $\begin{array}{l}\text { Partial } \\
\text { Lifetime trait }\end{array}$ & $\begin{array}{l}\mathrm{r}_{\mathrm{g}} \text { with } \\
\text { PL }\end{array}$ \\
\hline Age1C & -0.11 & & \\
\hline Age2C & -0.04 & PL2 & 0.13 \\
\hline Age $3 \mathrm{C}$ & 0.04 & PL3 & 0.21 \\
\hline Partial & $r_{g}$ with & Partial & $r_{g}$ with \\
\hline Lifetime trait & LDIM & Lifetime trait & LMY \\
\hline LDIM1 & 0.11 & MY1 & 0.28 \\
\hline LDIM2 & 0.19 & MY2 & 0.45 \\
\hline LDIM3 & 0.29 & MY3 & 0.56 \\
\hline Partial & $r_{g}$ with & Partial & $r_{g}$ with \\
\hline Lifetime trait & M/dLT & Lifetime trait & $\mathrm{M} / \mathrm{dPL}$ \\
\hline M/dLT1 & 0.51 & & \\
\hline M/dLT2 & 0.71 & M/dPL2 & 0.82 \\
\hline M/dLT3 & 0.82 & $\mathrm{M} / \mathrm{dPL} 3$ & 0.91 \\
\hline Partial & $r_{g}$ with & & \\
\hline Lifetime trait & $\mathrm{M} / \mathrm{dLDIM}$ & & \\
\hline M/dLDIM1 & 0.60 & & \\
\hline M/dLDIM2 & 0.82 & & \\
\hline M/dLDIM3 & 0.92 & & \\
\hline \multicolumn{4}{|c|}{ 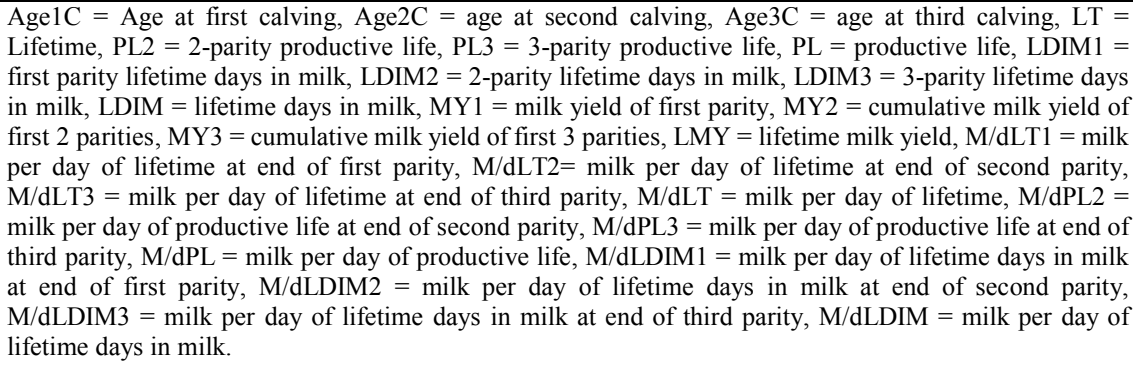 } \\
\hline
\end{tabular}

\section{CONCLUSION}

Results from this study showed that: (1) lifespan traits (LT, PL, LDIM and lifetime score) are strongly correlated with LMY indicating the economical importance of these traits, and (2) partial per-day milk yield traits for two-parities and three-parities had a relatively high correlation with their corresponding total LT perday milk yield traits. These partial traits are of practical use since they are easy to be calculated at any time during LT of the cow. Moreover, they combine different productive and reproductive aspects through LT of the animal. Therefore, good use of these traits would be helpful in determining best individuals early in life. Further genetic investigation is essentially needed to support results from this study and 
determine possibilities for genetic improvement of LT performance traits in Holstein Friesian cows in Egypt.

\section{REFERENCES}

Allaire, F. R., and J. P. Gibson, 1992. Genetic value of herd life adjusted for milk production. J. Dairy Sci., 75(5):1349- 1356.

Atil, H. and A. S. Khattab, 1999. Lifetime production and longevity of Holstein Friesian cows in relation to their sire transmitting ability. Pak. J. Biol. Sci.,2(1): 69-73.

Banks, B. D., I. L. Mao, and J. P. Walter, 1985. Robustness of the restricted maximum likelihood estimator derived under normality as applied to data with skewed distributions. J. Dairy Sci., 68(7):1785-1792.

Boettcher, P. J., L. K. Jairath, and J. C. M. Dekkers, 1999b. Pages 23-30 in Genetic Evaluation of Herd Life in Canada: Current Status and Future Outlook. Interbull Bull. No. 21. Jouy-en-Josas, France.

Cruickshank, J., K. A. Weigel, M. R. Dentine and B. W. Kirkpatrick, 2002. Indirect prediction of herd life in Guernsey dairy cattle. J. Dairy Sci., 85(5):1307-1313.

Dekkers, J. C. M., L. K. Jairath and B. H. Lawrence, 1994. Relationships between sire genetic evaluations for conformation and functional herd life of daughters. J. Dairy Sci., 77(3):844-854.

Dentine, M R, B. T. McDaniel, and H. D. Norman, 1987. Evaluation of sires for traits associated with herd life of grade and registered Holstein cattle. J. Dairy Sci., 70(12): 2623-2634.

Halawa, A.A.A., 2007. Longevity and age structure in dairy cattle. Ph.D. Thesis Fac. Agric., Ain Shams Univ., Egypt, 80pp.

Jairath, L.K., J.F. Hayes, and R.I. Cue, 1994. Multitrait restricted maximum likelihood estimates of genetic and phenotypic parameters of lifetime performance traits for Canadian Holsteins. J. Dairy Sci., 77(1):303-312.

Lormore, M. J., and D. T. Galligan, 2001. Economics of a typical lactation. J. Dairy Sci. 84 (E. Suppl.):E212-E215.

Madani, T., H. Yakhlef and M. Marie, 2008. Effect of age at first calving on lactation and reproduction of dairy cows reared in semi arid region of Algeria. Livestock research for rural development. 20:6. http://www.cipav.org.co/lrrd/ lrrd20/6/mada20092.htm.

Mulder, H., and G. Cansen, 2001. Derivation of economic values using lifetime profitability of Canadian Holstein cows. www.cdn.ca/committees/ Sept2001/MulderJansen.pdf.

Mwansa, P.B., 1997. Genetic analysis of longevity in the Canadian and New Zealand dairy herds. Ph. D. Thesis Fac. Graduated Studies., British Columbia Univ., Vancouver, Canada, 86pp.

Perez-Cabal, M.A. and R. Alenda, 2003. Lifetime profit as an individual trait and prediction of its breeding values in Spanish Holstein cows. J. Dairy Sci., 86(12):4115-4122.

Powell, R.L., 1985. Trend of age at first calving. J. Dairy Sci., 68(3):768-772.

SAS ${ }^{\circledR}$ Procedures Guide, Version 8.0, 1999.SAS Inst, nc., Cary, NC.

Vollema, A. R., and A. F. Groen, 1996. Genetic Parameters of Longevity Traits of an Upgrading Population of Dairy Cattle. J. Dairy Sci., 79(12):2261-2267. 
صفات الأداء مدى الحياة لماشية الهولثتين فريزيان المرباة في مصر

حارث عمر الحماد'، أسامة محمد السعيد'، محمد عبد العزيز محمد إبراهيم'، على عطية نجم'

ا - قسم الإتتاج الحيواني، كلية النزاعة، جامعة القاهرة، الجيزة، مصر، ب - دعهُ بحوث الإنتاج الحيوانس،

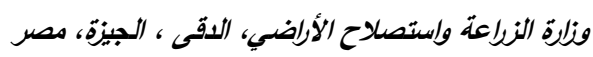

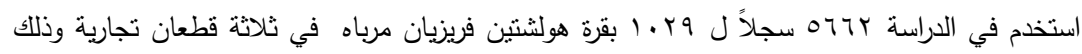

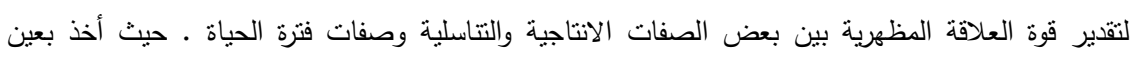

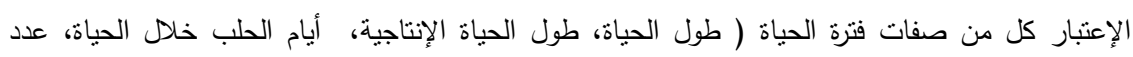

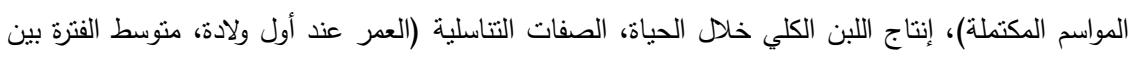

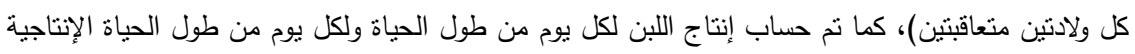

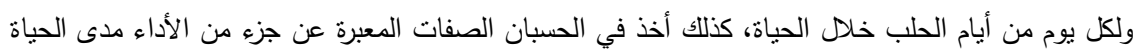
خلال الموسم الأول، و أول موسمين و المواسم الثلاثة الأولى.

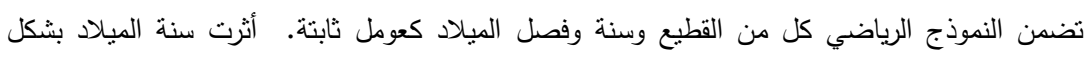

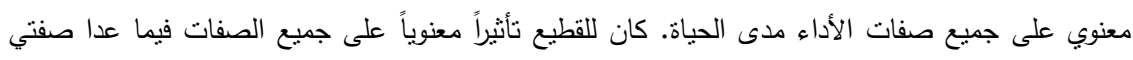

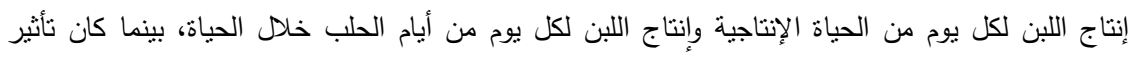

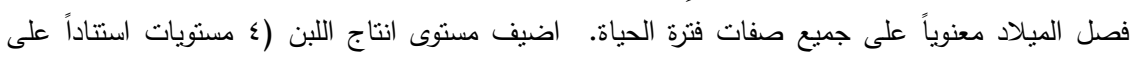

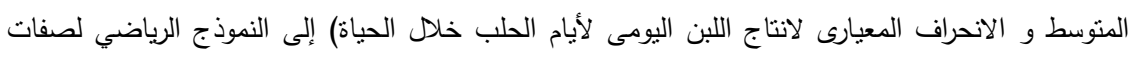

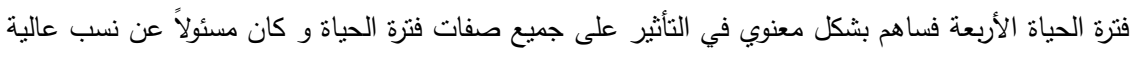

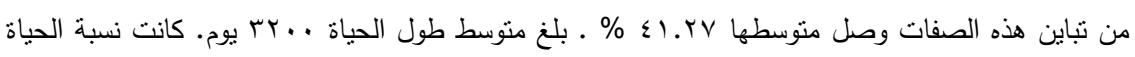

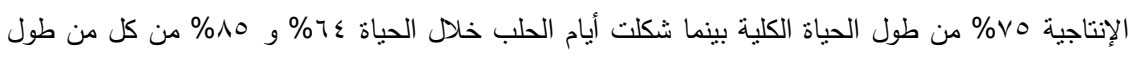

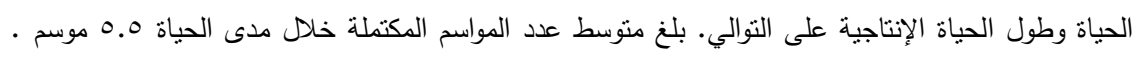

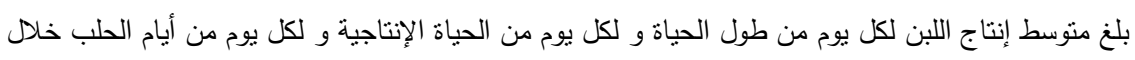

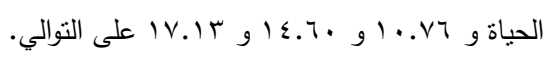

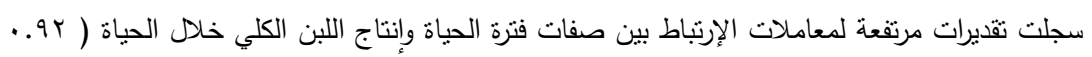
-

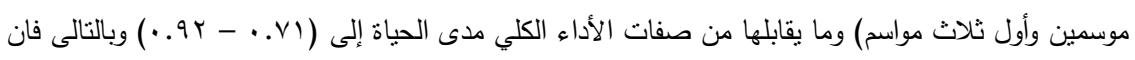

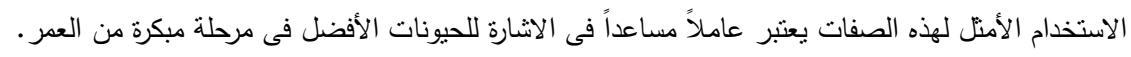

